\title{
Pollination of 'Hortblue Petite' Blueberry: Evidence of Metaxenia in a New Ornamental Home-garden Cultivar
}

\author{
Shirley Miller', Peter Alspach, Jessica Scalzo, and John Meekings \\ The New Zealand Institute for Plant and Food Research Limited, Plant and \\ Food Research Mt Albert, Private Bag 92169, Victoria Street West, Auckland \\ 1142, New Zealand
}

Additional index words. Vaccinium species, self-pollination, cross-pollination

\begin{abstract}
Hortblue Petite' (Vaccinium corymbosum L.) is a compact, small-statured tetraploid blueberry that was introduced to the New Zealand retail sector as a garden ornamental in 2005. Pollination requirements for 'Hortblue Petite' have not previously been investigated and this study was undertaken to better understand compatibility with other blueberry cultivars. Pollen donor effects on fruit weight were significant; pollen from large fruiting cultivars produced bigger fruit in 'Hortblue Petite', adding support toward metaxenia occurring in blueberry. Outcrossing with other tetraploids was most successful in terms of fruit set, berry weight, and yield potential. Number of viable seeds per berry was less with self-pollination and with crosses using pollen from a hexaploid rabbiteye type. The data indicated that the best yields would be obtained from using either open-pollinated flowers or a large-fruited cultivar such as 'Nui'.
\end{abstract}

Many fruit trees require cross-pollination to reach their full yield potential. In highbush blueberries (Vaccinium corymbosum L. and its hybrids), optimal pollination by genotype combination results in higher fruit set, larger berries, and earlier ripening (Bieniasz, 2007; Ehlenfeldt, 2001). Pollination effects have also been recorded in rabbiteye blueberries (V. virgatum syn. ashei Reade), particularly for fruit set (Brevis and NeSmith, 2005; ElAgamy et al., 1981; Payne et al., 1989). Both highbush and rabbiteye blueberries are available in retail garden centers for use in home gardens as are a number of different $\mathrm{Vacci}$ nium species (Trehane, 2004). Different fruiting characteristics between blueberry types, including maturation time, berry size, and yield, allow gardeners the opportunity to mix species and thereby extend the harvest season. Gardeners may also be interested in the visual effects of mass planting with a single type of ornamental blueberry. Whereas the need for cross-pollination between cultivars is widely acknowledged by commercial growers, there is little information available on cultivar compatibility for home gardeners. Thus, when a new blueberry cultivar becomes available to the retail sector, one of the first questions from a home gardener is whether the plant is selffertile and can be planted as a single specimen.

'Hortblue Petite' is a compact, smallstatured highbush blueberry cultivar, no more than $1.5 \mathrm{~m}$ in height. It was selected from open-pollinated seed of a dwarf tetraploid

Received for publication 22 July 2011. Accepted for publication 15 Sept. 2011.

${ }^{1}$ To whom reprint requests should be addressed; e-mail shirley.miller@plantandfood.co.nz.
V. corymbosum in New Zealand's temperate oceanic climate and introduced as an ornamental type to the New Zealand retail sector in 2005 (Scalzo et al., 2009). 'Hortblue Petite' has a low chill requirement compared with standard highbush blueberry varieties (e.g., 'Duke', 'Bluecrop', 'Elliott'), flowers prolifically in spring, and may have a second or third flowering event during the growing season if favorable conditions exist. The berries are small (less than 1.0 g) and dark blue in color with the main crop in New Zealand harvested in mid- to late December (Scalzo et al., 2009). 'Hortblue Petite' fruits prolifically in research plots, where bees are the main pollinator. Pollen is freely available for transfer from many sources including different Vaccinium species. However, there is little information on fruit set or yield of 'Hortblue Petite' in home gardens where pollen sources might be limited. It is generally accepted that self-fertility is low in most Vaccinium species (Chavez and Lyrene, 2009; Vander Kloet and Lyrene, 1987). Productivity of 'Hortblue Petite' in the home garden might be limited by insufficient pollen sources, particularly if the cultivar exhibits a degree of self-infertility.

This study was undertaken primarily to evaluate self- and cross-fertility of 'Hortblue Petite' with a number of other blueberry cultivars and genotypes. The wide variation in fruit size of genotypes used as pollenizers made it possible to explore a secondary aim to investigate effects of pollen source on fruit weight in 'Hortblue Petite', thus investigating evidence of metaxenia in blueberry.

\section{Materials and Methods}

Plant material. Thirteen 5-year-old plants of 'Hortblue Petite' growing in mounded rows at the Plant \& Food Research site in Hamilton, New Zealand (lat. $37^{\circ} 46^{\prime}$ S, long. $175^{\circ} 19^{\prime}$ E) were used. In Spring 2009, when the flowers were at the early bloom stage (i.e., 2 to $3 \mathrm{~d}$ before anthesis), they were emasculated by tearing away the corolla and immature stamens with small forceps as described by Galletta and Ballington (1996). Shoots with emasculated flowers were immediately enclosed in brown paper bags to exclude the possibility of pollination by visiting insects. Flowers were approximately at the same physiological stage of development when emasculated with the stigma almost fully extended but not sticky.

Pollination treatments. Each flower was pollinated twice: 2 and $4 \mathrm{~d}$ after emasculation (DAE). All flowers on a shoot were pollinated using pollen collected from one of six donors (Table 1). Five of the six pollen donors were tetraploids, whereas the remaining one, 'Ono', was hexaploid. Ploidy level was determined by flow cytometry (Ross Ferguson, personal communication). Cultivars 'Ono', 'Hortblue Onyx', and 'Hortblue Petite' are ornamental types; 'Nui' is a commercial cultivar; whereas Selections 1 and 2 are both highbush blueberry types under evaluation for commercial fruit growers.

Pollination was effected by lightly touching the stigmatic surface with a glass slide coated with pollen collected within the previous $24 \mathrm{~h}$ using the method described by Galletta and Ballington (1996). Bags were replaced after pollination and kept in place until the first fruit set assessment (14 to 18 DAE). In addition, a further 16 shoots on which flowers were left intact for natural pollination were tagged. The pollination treatments were spread over all plants so that each treatment was applied to at least 11 shoots on at least three plants, resulting in at least 47 flowers pollinated and 34 fruit set per pollen parent (Table 1).

Pollen viability in blueberry is normally over $90 \%$ and was not checked on this occasion. Pollen on the stigmas and pollen tube growth through the styles to the ovaries was assessed using the method developed for kiwifruit (Actinidia chinensis Planch.) by Hopping and Jerram (1979).

Measurements. Fruit set was estimated as the proportion of pollinated flowers that had produced green fruit 1 to 3 weeks after anthesis. Fruit drop was calculated as the difference between fruit set and number of fruit harvested per flowers pollinated. Individual fruit were harvested as they ripened (greater than $90 \%$ blue in color) and maturation time determined as the number of days from the first pollination until average fruit harvest date. All fruit were weighed and yield potential for each cross determined as the percentage of fruit set 3 weeks after pollination multiplied by mean fruit weight. Because all pollinations were conducted on 'Hortblue Petite', that fact that yield potential excludes the original number of flowers does not impact on its validity as a measure of the effect of pollen donor on potential yield. Harvested fruit were stored at $4{ }^{\circ} \mathrm{C}$ until seed extraction. Total numbers of seed per fruit and numbers of viable seed (determined by germination tests) were recorded for each of $\approx 25$ ( \pm 5 ) randomly chosen fruit from each cross. 
Table 1. Number of flowers pollinated, fruit set, and description of pollen donors used in self- and crosspollination of 'Hortblue Petite' blueberry.

\begin{tabular}{lllcccc}
\hline Pollen donor & $\begin{array}{c}\text { Vaccinium } \\
\text { species }\end{array}$ & Main use & $\begin{array}{c}\text { Ploidy } \\
\text { level }\end{array}$ & $\begin{array}{c}\text { No. of flowers } \\
\text { pollinated }\end{array}$ & $\begin{array}{c}\text { No. of } \\
\text { fruit set }\end{array}$ & $\begin{array}{c}\text { No. of } \\
\text { plants }\end{array}$ \\
\hline 'Nui' & V. corymbosum & Commercial & $4 \times$ & 96 & 74 & 6 \\
Selection 1 & V. corymbosum & Commercial & $4 \times$ & 47 & 43 & 7 \\
Selection 2 & V. corymbosum & Commercial & $4 \times$ & 81 & 58 & 3 \\
'Hortblue Petite' & V. corymbosum & Ornamental & $4 \times$ & 67 & 48 & 6 \\
'Hortblue Onyx' & V. simulatum & Ornamental & $4 \times$ & 88 & 50 & 8 \\
'Ono' & V. virgatum & Ornamental & $6 \times$ & 84 & 34 & 6 \\
OP & - & - & - & 135 & 102 & 7 \\
\hline
\end{tabular}

$\mathrm{OP}=$ open-pollinated

Data analysis. Linear mixed models were fitted to the variates of interest (e.g., fruit set, fruit weight) with pollen donor as a fixed effect and plant and, for those variates measured on individual fruit, shoot (within plant) as random effects. For percentage fruit set, fruit drop, and seed germination, binomial errors were fitted (with the logit link function). The relationship between fruit weight and number of viable seed was similarly modeled. Here the fixed effects were number of viable seeds and pollen donor (and their interaction, although this was dropped because it did not contribute significantly to the overall fit). This relationship was used to estimate the fruit weight for each pollen donor treatment for a given number (i.e., 10) viable seed per fruit. The possibility of pollen donor effects on fruit weight in 'Hortblue Petite' independent of seed number was investigated by comparing this estimate with the average fruit weight of the donor cultivars. The latter was determined using fruit data collected between 2001 and 2009 for each of the six donor cultivars growing in the germplasm repository next to the 'Hortblue Petite' trial site. Data were available for between 1 and 4 years per cultivar. Because both the estimates of the pollen donor fruit weights and the resulting 'Hortblue Petite' fruit weights had associated SES, a parametric bootstrap with 10,000 runs was used to estimate the $95 \%$ confidence limits of the linear regression coefficients.

Residual plots were examined to control for outliers and confirm that the underlying assumptions of the analyses were valid. All statistical analyses and graphics were conducted using R 2.13.0 (R Development Core Team, 2011) and the mixed models were fitted using the lme4 package (Bates et al., 2011).

\section{Results}

Pollen germination. Observations of the stigmatic surface and styles after pollination showed large numbers of pollen grains on the stigmas for all flowers, including self-pollinations. Pollen tubes germinated and reached the base of the style within $24 \mathrm{~h}$ of pollination (Fig. 1). No differences between pollen donors were observed at the pollination stage.

Fruit set. Pollen donor had a detectable effect on all variates $(P<0.01$; Fig. 2$)$ except for number of seed per fruit (data not shown). At the first assessment, 3 weeks after the first pollination, fruit set was $50 \%$ or better for all crosses. The open-pollinated treatments set the most fruit. Pollen from the $(6 \times)$ rabbiteye cultivar Ono resulted in the lowest fruit set (Fig. 2A). Fruit set from self-pollinated flowers was intermediate between these two. Fruit drop (i.e., between the first fruit set assessment and harvest) was $\approx 10 \%$ to $20 \%$, except when 'Ono' was the pollen donor, in which case fruit drop was $\approx 40 \%$ (Fig. 2 B)

Ripening interval. Maturation time from first pollination to mean harvest date was at least $5 \mathrm{~d}$ longer with the self-cross $(P<0.01$; Fig. 2C). Maturation time was similar for the other crosses, including the hexaploid rabbiteye 'Ono' cross.

Fruit weight, viable seeds, and pollen donor. Fruit weight for the self-cross was low as was the fruit weight when 'Hortblue Onyx' was the pollen donor (Fig. 2D). Fruit weight was moderate when 'Ono' was used as the pollen donor, but the number of viable seed per fruit was low (Fig. 2D-E). Seed viability was also significantly reduced for self-pollinated flowers (Fig. 2E).

There was a positive linear relationship between the fruit weight and the number of viable seed per fruit $[0.010 \mathrm{~g}$ ( SE $0.0017 \mathrm{~g}$ ) increase in fruit weight for every extra seed; Fig. 3]. Although no differences between the slopes of this relationship resulting from the pollen donor were detected, there was some evidence that the intercept varied according to the pollen donor $(P=0.070)$. That is, the fruit weight for a given number of seeds differed according to the donor, and this difference was the same irrespective of the number of seeds. The difference was related to the average fruit weight of the pollen donor such that 'Hortblue Petite' fruit originating from fertilization with pollen from selections with large fruit tended to be larger, for a given number of viable seed, than fruit originating from fertilization with small-fruited selections (Fig. 4). On average, a 1-g increase in the average fruit weight of the (pollen) donor cultivar led to an $\approx 0.054 \mathrm{~g}$ ( $95 \%$ bootstrap confidence interval, 0.007 to $0.105 \mathrm{~g}$ ) increase in the average weight of the resulting fruit. If selfed fruit were excluded, this donor effect was slightly reduced to 0.044 $\mathrm{g}$ and the $95 \%$ confidence interval spanned 0 ( -0.009 to $0.100 \mathrm{~g})$.

Yield potential. Calculation of yield potential indicated that the best yields would be obtained from using either 'Nui' or openpollinated flowers (Fig. 2F).

\section{Discussion}

Although there have been numerous pollination studies carried out for the benefit of

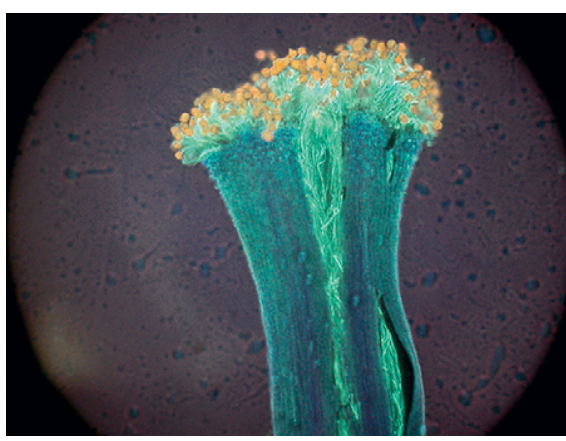

Fig. 1. 'Hortblue Petite' self-pollination showing pollen grains on the stigma with germ tubes extending down the style $24 \mathrm{~h}$ after pollination.

commercial blueberry farms, there is very little information available for the home garden sector. Results reported in this article refer to a blueberry cultivar bred specifically for that market (Scalzo et al., 2009).

Fruit set in 'Hortblue Petite' was optimized by cross-pollination with compatible genotypes and was highest with open pollination. Pollinating insects (mostly bees) make multiple visits to flowers and are likely to be less damaging to the stigmatic surface than a glass slide. With open pollination, bees deposit pollen from a variety of sources provided those sources are available, some of which are more compatible than others with the maternal tissues (Vander Kloet, 1991). Results from the present study are consistent with this observation and add support to the suggestion of Brevis and NeSmith (2005) that source of pollen deposited plays an important role in determining fruit set in blueberries. Although cross-pollination was better, 'Hortblue Petite' appears to have a high degree of self-fertility and can exhibit adequate fruit set under field conditions without crosspollination. However, with self-pollination, fruit size may be reduced and ripening delayed. Similar effects were reported by Bieniasz (2007), Ehlenfeldt (2001) and Lang and Danka (1991), whereas Vander Kloet (1991) also showed that when the number of compatible pollen donors is increased one at a time, the effect on seed set is cumulative with each additional pollen donor eliciting an average increment of two or three seeds per berry. Partial incompatibility between tetraploid highbush and hexaploid rabbiteye types helps to explain the reduced fruit set, high fruit drop, and low numbers of viable seed with pollen from the rabbiteye cultivar Ono. It would appear that 'Hortblue Petite' is similar to other blueberries in that there is potential for $100 \%$ fruit set provided the plants receive adequate cross-pollination with a compatible species (Chavez and Lyrene, 2009).

The lack of difference in behavior between pollen donors with respect to pollen tube growth in the first $24 \mathrm{~h}$ after pollination was not unexpected. Similar results were reported by Krebs and Hancock (1988), who later postulated a post-zygotic mechanism (seed abortion) as the basis for fertility differences in tetraploid $V$. corymbosum (Krebs and Hancock, 1990). Wenslaff and Lyrene (2001) suggested that the first pollination is the most important in 
A

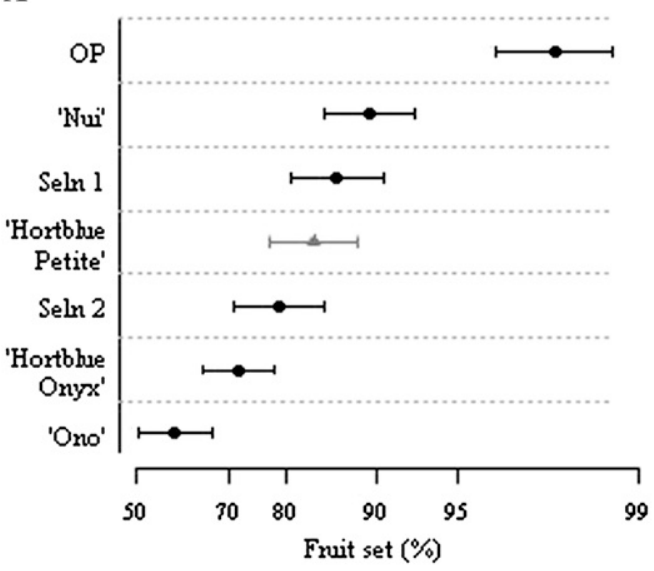

C

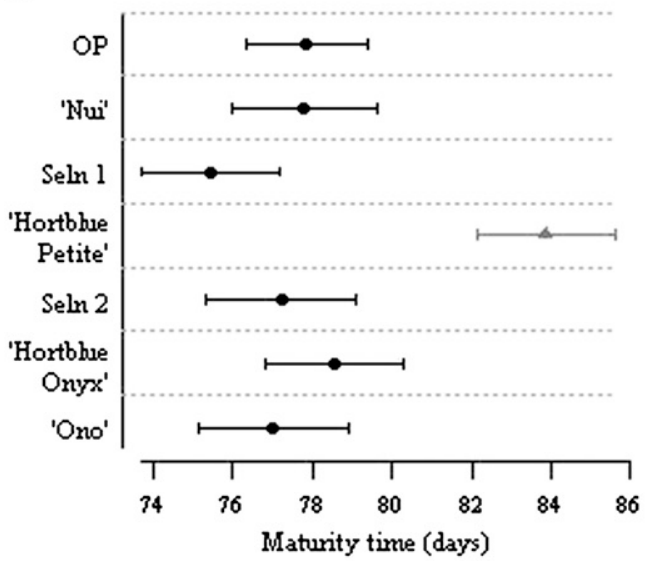

$\mathbf{E}$

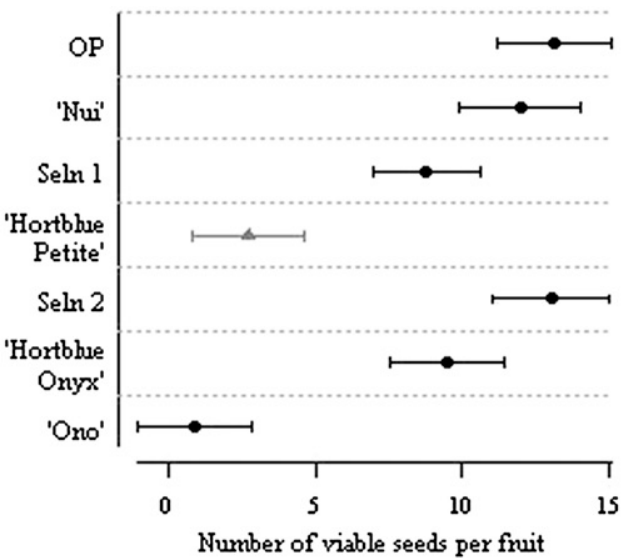

B

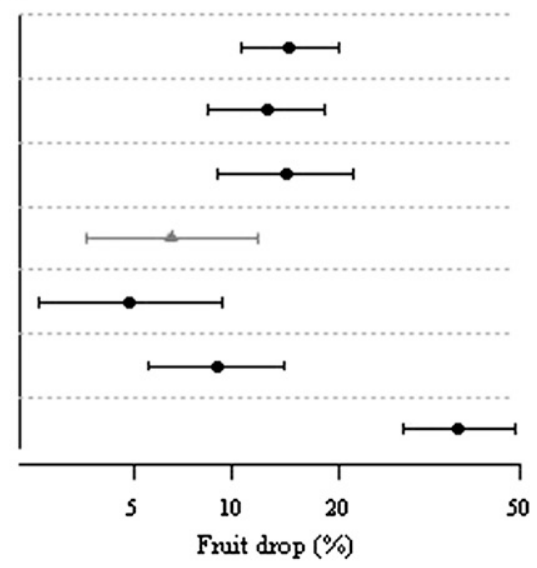

D

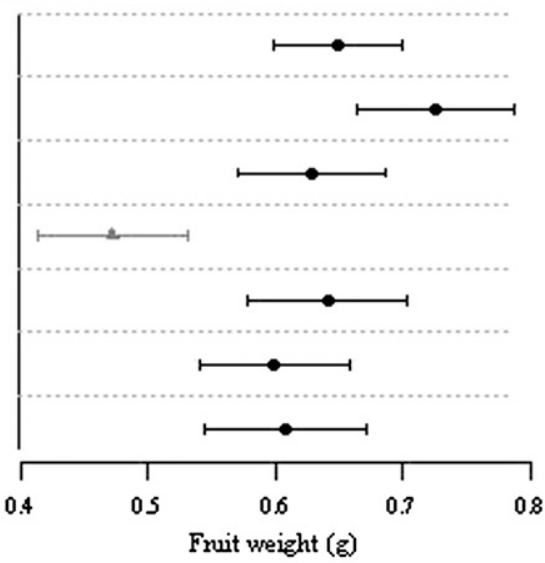

$\mathbf{F}$

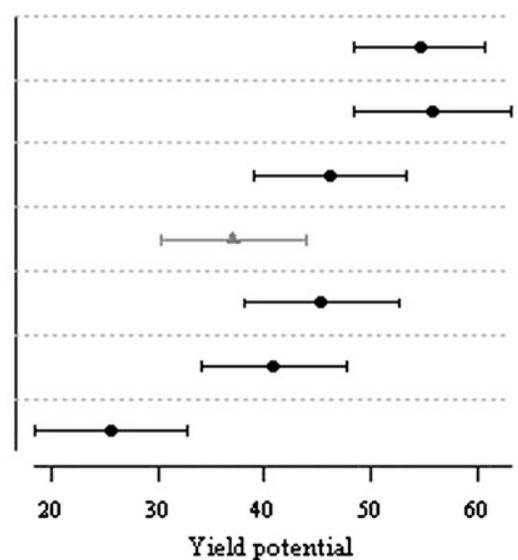

Fig. 2. (A-F) Dot plots showing the best linear unbiased estimators $( \pm \mathrm{SE})$ for six of the variates for each blueberry pollen donor. Pollen donors are ordered according to fruit set, and 'Hortblue Petite' is distinguished by gray triangles. Note logit scale for percentage values on first two figures (A-B).

at least some blueberry cultivars. It produces the majority of seed in a berry regardless of subsequent pollen applications. Post-fertilization expression of reduced self-fertility (ovule abortion) is a possible explanation for the low number of viable seed in the self-cross.

In our study, cross-pollination of 'Hortblue Petite' produced fruit with an average of $\approx 10$ viable seeds per berry. Like with most previous studies in blueberry, there was a positive correlation between berry weight and berry seed content (Ehlenfeldt, 2001; Lang and Danka, 1991). Furthermore, there was a trend toward pollen donor effects on fruit weight.
Use of a pollen donor with typically large fruit to pollinate 'Hortblue Petite' resulted in larger fruit being produced. Gupton (1997) used the term xenia to describe pollen donor effects on fruit development period in blueberries and suggested that berry weight may also be increased in southern highbush cultivars. However, although metaxenia has been reported for other fruit crops [e.g., raspberry (Colbert and de Oliveira, 1990) and cherimoya (Kahn et al., 1994)], evidence for metaxenia is still inconclusive for blueberry. On reanalysis of Gupton's results, Ehlenfeldt (2003) observed several anomalies in the data and was unable to show reliable differences resulting from pollen source effects in highbush blueberry cultivars. He concluded that differences resulting from pollen sources were inconsistent. By modeling our data set and using unbiased estimators for fruit weight, we have demonstrated pollen donor effects on fruit weight in 'Hortblue Petite'. Much of this effect can be attributed to differences in the number of viable seeds. However, our analysis has suggested that when the number of viable seeds per fruit is standardized, then pollen from donors with larger fruit tended to result in larger berries of 'Hortblue Petite'. Whereas this possible 


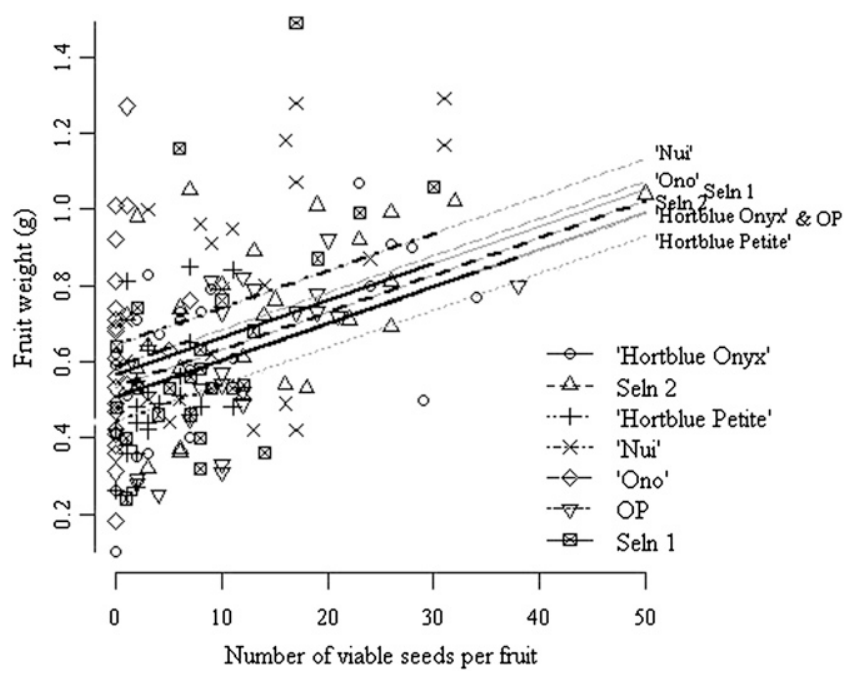

Fig. 3. Scatterplot showing the relationship between 'Hortblue Petite' fruit weight and the number of viable seeds per fruit. The fitted lines, from the mixed modeling, are shown for each pollen donor with the thicker dark line extending only as far as the range of seed numbers observed for each donor. The points, coded by donor, show the actual observed values and as such contain between-plant and between-shoot (within plant) variation.

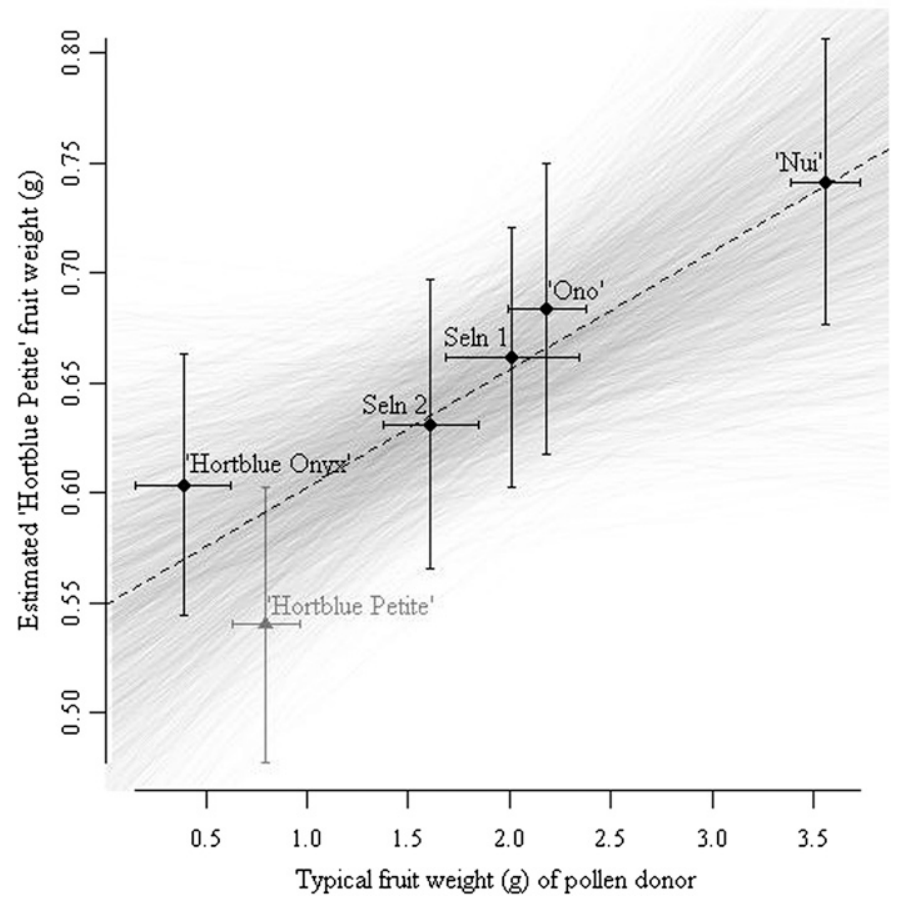

Fig. 4. Scatterplot of the relationship between the best linear unbiased estimators for the weight of a fruit of 'Hortblue Petite' with 10 seeds ( $\pm 1 \mathrm{SE}$ ) when pollinated by one of six selections and the typical fruit weight $( \pm 1 \mathrm{SE}$ ) of that selection. The dashed line shows the median linear fit from the parametric bootstrap, and the semitransparent gray lines are 2000 individual fits (see text for details).

metaxenia effect is too small to be of commercial value, it is of scientific interest if it can be confirmed by further work with other genotypes.

Yields obtained in monoclonal conditions may not be as high as those from mixed cultivar plantings where outcrossing is maximized (Hanson and Hancock, 1990). Calculation of yield potential showed that for 'Hortblue Petite', the reduction may be as much as one-third. Whereas this would be a problem in a commercial situation, it may be acceptable for home gardeners. However, gardeners would be well advised to plant another tetraploid cultivar with 'Hortblue Petite' if they wish to maximize yields.

\section{Literature Cited}

Bates, D., M. Maechler, and B. Bolker. 2011. lme4 Linear mixed-effects models using S4 classes. R package version 0.999375-39. 18 Aug. 2011. $<$ http://CRAN.R-project.org/package=lme4>.

Bieniasz, M. 2007. Effects of open and self pollination of four cultivars of highbush blueberry (Vaccinium corymbosum L.) on flower fertilization, fruit set and seed formation. J. Fruit and Ornamental Plant Res. 15:35-40.

Brevis, P.A. and D.S. NeSmith. 2005. Transport of cross-pollen by bumblebees in a rabbiteye blueberry planting. HortScience 40:2007-2010.

Chavez, D.J. and P.M. Lyrene. 2009. Effects of self-pollination and cross-pollination of $\mathrm{Vacci}$ nium darrowii (Ericaceae) and other low-chill blueberries. HortScience 44:1538-1541.

Colbert, S. and D. de Oliveira. 1990. Influence of pollen variety on raspberry (Rubus idaeus L.) development. J. Hered. 81:434-437.

Ehlenfeldt, M.K. 2001. Self- and cross-fertility in recently released highbush blueberry cultivars. HortScience 36:133-135.

Ehlenfeldt, M.K. 2003. Investigations of metaxenia in northern highbush blueberry (Vaccinium corymbosum L.) cultivars. J. Amer. Pomol. Soc. 57:26-31.

El-Agamy, S.Z.A., W.B. Sherman, and P.M Lyrene. 1981. Fruit set and seed number from self- and cross-pollinated highbush $(4 \times)$ and rabbiteye (6x) blueberries. J. Amer. Soc. Hort. Sci. 106:443-445.

Galletta, G.J. and J.R. Ballington. 1996. Blueberries, cranberries and lingonberries, p. 1-107. In: Janick, J. and J.N. Moore (eds.). Fruit breeding, Volume 2, Vine and small fruits. John Wiley \& Sons, New York, NY.

Gupton, C.L. 1997. Evidence of xenia in blueberry. Acta Hort. 446:119-123.

Hanson, E.J. and J.F. Hancock. 1990. Highbush blueberry cultivars and production trends. Fruit Var. J. 44:77-81.

Hopping, M.E. and E.M. Jerram. 1979. Pollination of kiwifruit (Actinidia chinensis Planch.): Stigma-style structure and pollen tube growth N.Z. J. Bot. 17:233-240.

Kahn, T.L., C.J. Adams, and M.L. Arpaia. 1994. Paternal and maternal effects on fruit and seed characteristics in cherimoya (Annona cherimola Mill.). Sci. Hort. 59:11-25.

Krebs, S.L. and J. Hancock. 1988. The consequences of inbreeding on fertility in Vaccinium corymbosum L. J. Amer. Soc. Hort. Sci. 113:914-918.

Krebs, S.L. and J.F. Hancock. 1990. Early-acting inbreeding depression and reproductive success in the highbush blueberry, Vaccinium corymbosum L. Theor. Appl. Genet. 79:825-832.

Lang, G.A. and R.G. Danka. 1991. Honey-bee-mediated cross- versus self-pollination of 'Sharpblue' blueberry increases fruit size and hastens ripening. J. Amer. Soc. Hort. Sci. 116:770-773.

Payne, J.A., J.H. Cane, A.A. Amis, and P.M. Lyrene. 1989. Fruit size, seed size, seed viability and pollination of rabbiteye blueberries ( $\mathrm{Vacci}$ nium ashei Reade). Acta Hort. 241:38-42.

R Development Core Team. 2011. R: A language and environment for statistical computing. $\mathrm{R}$ Foundation for Statistical Computing, Vienna, Austria. ISBN 3-900051-07-0. 18 Aug. 2011. $<$ http://www.R-project.org/>

Scalzo, J., S. Miller, C. Edwards, and P. Alspach. 2009. 'Hortblue Onyx' and 'Hortblue Petite' Two new ornamental blueberries from New Zealand. Acta Hort. 810:153-156.

Trehane, J. 2004. Blueberries, cranberries and other Vacciniums. Timber Press, Inc., Cambridge, UK.

Vander Kloet, S.P. 1991. The consequences of mixed pollination on seed set in Vaccinium corymbosum. Can. J. Bot. 69:2448-2454.

Vander Kloet, S.P. and P.M. Lyrene. 1987. Selfincompatibility in diploid, tetraploid, and hexaploid Vaccinium corymbosum. Can. J. Bot. 65:660-665.

Wenslaff, T.F. and P.M. Lyrene. 2001. Results of multiple pollination in blueberry (Vaccinium elliottii Chapm.). Euphytica 117:233-240. 